\title{
Adeus ao Trabalho? \\ ENSAIO SOBRE AS METAMORFOSES E A CENTRALIDADE DO MUNDO DO TRABALHO (Ricardo Antunes)
}

\author{
Jair Batista*
}

Apresentado como tese de livre-docência em sociologia do trabalho no IFCHUNICAMP, "Adeus ao trabalho?" alcançou em pouco tempo um sucesso surpreendente. A prova disso foi a rapidez com que se esgotou a primeira edição.

O livro está dividido em quatro capítulos, além do apêndice que contém vários artigos publicados em revistas nacionais e estrangeiras. Pela forma como foi organizado e escrito propicia uma leitura fácil e envolvente, não obstante as complexas questões que coloca para discussão, tais como: o operariado fabril estaria em vias de desaparecer? A diminuição da classe trabalhadora aponta para a perda de importância deste segmento social? Que conseqüências tiveram estas modificações para os sindicatos? A categoria trabalho não é mais central na sociedade contemporânea? Estas são as principais indagações sobre as quais o autor busca refletir . Entretanto, perguntaria o leitor, qual seria a novidade de "ADEUS AO TRABALHO?" dado que estas questões vêm sendo alvo de um amplo debate no seio das ciências sociais e, particularmente, na área da sociologia do trabalho? Pois, então, vejamos.

O primeiro capítulo, intitulado "Fordismo, Toyotismo e Acumulação Flexível" discute as transformações ocorridas no mundo do trabalho e seus impactos sobre a subjetividade dos trabalhadores. Nas palavras do autor: "Foram tão intensas as modificações, que se pode mesmo afirmar que a classe-que-vive-do-trabalho sofreu a mais aguda crise deste século, que atinge não só sua materialidade, mas teve profundas repercussões na sua subjetividade e ... afetou sua forma de ser"'(pág. 15).

\footnotetext{
* Estudante de Ciências Sociais - UFBA e bolsista de Iniciação Científica do projeto "A Reestruturação Produtiva e os sindicatos - um estudo da imprensa sindical", realizado no CRH com o apoio do PIBIC/CNPq-UFBA, sob orientação da Prof a Graça Druck, a quem agradeço pelas sugestões feitas ao texto.
}

CADERNO CRH, Salvador, n.24/25, p.299-302, jan./dez. 1996 
Considerando que o mundo do trabalho se apresenta multiforme, onde modelos de gestão substituem-se e mesclam-se a outros, o autor contesta a existência do fordismo e do taylorismo como únicos processos produtivos, mostrando que a estes juntam-se novos padrões de gestão/organização do trabalho como "neofordismo", o "neotaylorismo", o "posfordismo" e o "toyotismo" ("Modelo japonês" que até agora tem conseguido um nível de propagação extraordinária), os quais seriam, segundo o autor, uma resposta à crise do fordismo. Fazem parte de uma nova etapa de reestruturação da produção que se insere no processo de acumulação de capital em escala ampliada, onde essas novas formas de gestão cumpririam papel privilegiado, no sentido de oferecer ao capital as melhores e mais eficientes formas de exploração da força de trabalho, com a finalidade de obter resultados mais satisfatórios no processo de produção de riqueza.

Dentre esses novos processos produtivos, dois merecem destaque especial: acumulação flexível e o toyotismo. O primeiro tendo a Terceira Itália como cenário "tem possibilitado o advento de uma nova forma produtiva que articula, de um lado um significativo desenvolvimento tecnológico, do outro uma descentração produti$v a$ "(pág. 17). O segundo, o toyotismo que combinando a experiência da indústria têxtil com a gestão de supermercado(kanban) na indústria automobilística propiciou um extraordinário desenvolvimento do parque industrial japonês. No caso da indústria têxtil um trabalhador opera várias máquinas, na Toyota, em média seis. No caso do processo $\operatorname{Kanban}^{1}$ a produção orienta-se no sentido de recolocar o produto no estoque logo após a sua venda. Ou seja, é a partir da venda que se inicia o processo produtivo. Esta orientação o distingue basicamente em relação ao fordismo, pois é o consumo que orienta a produção e não o contrário, como ocorre em uma produção de base fordista.

Aliado a isso o toyotismo mostrou-se eficiente na luta contra a ação do sindicatos japoneses, como afirma o autor: "... havia que enfrentar o combativo sindicalismo japonês responsável por uma atuação marcada por vários conflitos grevistas". Após a vitória sobre o movimento sindical as empresas "criaram o que se constitui no traço distintivo do sindicalismo japonês da era toyotista: o sindicalismo por empresa, o sindicato-casa"(pág. 25).

Contrariando aqueles que pregam a adoção do modelo japonês no Ocidente o autor enfatiza a sintonia entre o neoliberalismo e o toyotismo, vaticinando: “... não temos dúvida em enfatizar que a ocidentalização do toyotismo ... conformaria em verdade uma decisiva aquisição do capital contra o trabalho". (pág. 33).

As mudanças em curso no mundo do trabalho é a temática do segundo capítulo. Nele o autor revela as tendências encontradas nos países de capitalismo avançado, onde a classe trabalhadora apresenta-se cada vez mais complexificada, fragmentada e heterogeneizada. Acentua o caráter contraditório dessas mudanças onde, de um

${ }^{1}$ Sistema de placas que são utilizadas para indicar a necessidade de reposição das peças que estão faltando. 
lado, há um processo de qualificação do trabalho através de sua maior intelectualização e, de outro, o processo inverso de desqualificação, precarização do trabalho. Segundo o autor, as transformações apontam ainda para redução do número de trabalhadores do setor fabril e o extraordinário incremento do assalariamento no setor de serviços. Além disso, ANTUNES aponta a tendência de redução dos empregos em tempo integral nos países ditos "centrais" acompanhada, simultaneamente pelo crescimento do trabalho em tempo parcial, precário, subcontratado, etc., ressaltando-se, também, neste processo contraditório de mudanças, o incremento do trabalho feminino. O resultado destas transformações é a constituição de uma classe trabalhadora cada vez mais complexa e heterogênea.

A título de conclusão, poderíamos dizer, portanto, que as principais análises levantadas neste capítulo do livro apontam para os seguintes processos: 1) fragmentação, complexificação e heterogeneização da classe trabalhadora; 2) qualificação e desqualificação do trabalho; 3) desemprego estrutural; 4) incremento do trabalho feminino; 5) trabalho precário, temporário, parcial, subcontratado, terceirizado.

Em seguida, ANTUNES discute a crise dos sindicatos. Há uma crise do sindicalismo? Quais as particularidades desta crise? Quais os principais desafios do movimento sindical? Essas são as indagações que o autor procura responder no $3^{\circ}$ capítulo do livro.

Um indicativo da crise dos sindicatos constitui-se na tendência da queda à taxa de sindicalização, durante a década de 80 , para os países avançados e, na virada da década de 80 e início do anos 90, para os países do terceiro mundo. Ao lado desta tendência um outro fator que evidencia a crise do movimento sindical seria a dificuldade de superar a distância entre os trabalhadores "estáveis" e os trabalhadores terceirizados, temporários, subcontratados que um sindicalismo verticalizado da era fordista tem sido incapaz de romper. Por fim, juntam-se aos fatores anteriores a "intensificação da tendência neocorporativa, que procura preservar os interesses do operariado estável” .

Para o autor, a crise do movimento sindical se acentua com o desenvolvimento das seguintes tendências: 1) individualização das relações de trabalho; 2) desregulamentação e flexibilização do mercado de trabalho; 3) crise das entidades sindicais, que se expressa através da burocratização e institucionalização de sua ação; 4) ação ideológica e manipulatória do capital.

O movimento sindical seria capaz de romper com a distância que separa trabalhadores estáveis daqueles terceirizados, precários temporários? de romper com neocorporativismo? de romper com o sindicato-casa da era toyotista? de estruturar um sindicalismo horizontalizado, que englobe o conjunto da classe trabalhadora e, portanto, supere o sindicalismo verticalizado, característica da era fordista? de romper com a institucionalização e burocratização das entidades sindicais? de a- 
vançar para além de uma ação...defensiva ...que caminhe na direção da emancipação dos trabalhadores? Estes são os desafios que, segundo o autor, estão colocados para o movimento sindical neste final de século.

O debate sobre a crise da sociedade do trabalho é o tema da quarta parte do livro, onde ANTUNES polemizando com OFFE, GORZ e HABERMAS aponta para a imprecisão das análises destes autores justamente por não perceberem a dupla dimensão do trabalho. Isto é, o trabalho na sua dimensão concreta, como produtor de coisas socialmente úteis e o trabalho na sua dimensão abstrata, que produz valores de troca. É este o eixo a partir do qual ele situa a maior fragilidade das formulações dos críticos da sociedade do trabalho. “... sem a devida incorporação desta distinção entre trabalho concreto e abstrato, quando se diz um adeus ao trabalho, comete-se um forte equívoco analítico, pois considera-se de maneira una um fenômeno que tem dupla dimensão. (pág.79)", o que, por conseguinte, tem levado muitos destes críticos a definir a sociedade atual, como sociedade do serviço, da informação, pós-industrial, etc. Da mesma forma, segundo ANTUNES, ao declararse um "adeus proletariado" deixa-se de perceber o trabalho como momento de mediação entre o homem e a natureza; como atividade estruturante do "ser social". Conclui, portanto, que os embates que se dão no âmbito do mundo trabalho têm estatuto de centralidade, ao declarar: "... A revolução dos nossos dias é...uma revolução no e do trabalho...", e segue: “... Por isso, não concordamos com as teses que propugnam o desaparecimento das ações de classe...". Finalizando, demonstra que as experiências: alemã, japonesa, americana, sueca, não significaram a eliminação do estranhamento, seja pela maior intelectualização do trabalho seja pelo "envolvimento manipulatório". Em muitos casos deu-se justamente sua intensificação, não sua eliminação.

Para concluir gostaria de recomendar a leitura de dois textos presentes no apêndice. O primeiro uma resenha sobre o livro de ROBERT KURZ ("O Colapso da modernização - da derrocada do socialismo de caserna à crise da economia mundial) que discute a queda dos regimes do leste europeu e a crise da sociedade capitalista. O segundo "Trabalho e Estranhamento", onde a questão do trabalho como ponto de partida do processo de humanização do "ser social" e a particularidade do estranhamento e da alienação na sociedade capitalista são debatidos. Estas são as principais questões, ao nosso ver, que este instigante livro procura discutir.

LIVRO: Adeus ao Trabalho? Ensaio Sobre as Metamorfoses e a Centralidade do Mundo do Trabalho

AUTOR: Ricardo Antunes

Ed. Cortez/ Ed. da UNICAMP; SP; 1994. 